\title{
New challenges in sport entrepreneurship for value creation
}

\begin{abstract}
Sport entrepreneurship has rapidly gained popularity in the entrepreneurship, management and sports fields due to the way it balances practice with theory. Despite the increased interest in sport entrepreneurship there is still much to know about how sport is entrepreneurial and how it affects other entrepreneurship areas. This means it is crucial to develop new research paths on sport entrepreneurship that incorporate digital technologies that are emerging in the global business environment. This paper focuses on the role of digital transformation in influencing value co-creation activities in sport. This includes focusing on how to take a design thinking approach in order to strategize about future potential innovations affecting sport. Managerial implications and future research suggestions are stated that highlight the interplay between sport entrepreneurship innovation and knowledge.
\end{abstract}

Key words: digital transformation, entrepreneurship, innovation, knowledge management, sport

\section{Introduction}

Sport entrepreneurship constitutes a nascent field of entrepreneurship research that has some way to go in terms of research development (Pellegrini, Rialti, Marzi and Caputo, 2020). The sport entrepreneurship literature has significantly increased in the last five years due to interest in studying the innovative, competitive and forward thinking actions of sport entities. Sport entrepreneurship can be described as a systematic development of an idea related to 
sport. This means there is a set of objectives that need to be fulfilled in order for the idea to progress in the marketplace. Sport is a natural setting for entrepreneurship due to the need to continuously change and adapt (Jones, Jones, Williams-Burnett and Ratten, 2017).

Entrepreneurship is important to the sport industry as it is a driver of change and innovation (Ball, 2005). This study addresses the accelerated interest in health and lifestyle trends in sport by extending the current research. Sport entrepreneurship is viewed in this study from a fitness and lifestyle perspective. Therefore, it is defined as "a set of connections and interactions regarding fitness and health interests with the goal of developing a business idea". This definition emphasises both the process component of sport entrepreneurship and the performance outcome.

The origins of research on sport entrepreneurship derive from knowledge inquiries about the use of new elements into the market that improve current conditions. This means that sport entrepreneurship will likely have flow on effects to other sectors of the economy (HuertasGonzalez-Serrano, Jones and Llanos-Contrera, 2020). Thus, sport entrepreneurship can mean a change in the production system that has broad ramifications even if the level of innovation is low. The sport entrepreneurship literature can be divided into four main areas: the importance of entrepreneurship to sport, the impact of innovation on sport, entrepreneurial strategies in sport, and technologies supporting the use of entrepreneurship in sport. The use of entrepreneurship in a sport context is acknowledged by sport teams, organisation's and governments as a way to improve performance (Escamilla-Fajardo, Nunez-Pomar, PradoGasco and Ratten, 2019). The importance of entrepreneurship in sport has coincided with entrepreneurship in general garnering popularity as a way to solve existing problems but also by providing better services. This has led to the sport industry being impacted by entrepreneurship in a variety of ways from the establishment of mobile commerce applications to integrating new technology into existing businesses (Koronios, Kriemadis and 
Papadopoulos, 2019). This has resulted in entrepreneurship strategies being used in sport on a regular basis in order to see new possibilities emerge (Jaklic, Grubljesic and Popovic, 2018). Thus, more sport managers and sport organisations are focusing on how to act in a more entrepreneurial manner. This is due to entrepreneurship acting as a central nervous system in sport by connecting different systems to new ideas, which makes it is of vital importance to sport entities that they have open and fluent communication with other entities. This will enable the development of close relationships that facilitate the sharing of pertinent knowledge (Fakhar-Manesh, Pellegrini, Marzi and Dabic, 2019). Despite this importance some sport organisations are not fully aware of the potential of entrepreneurship.

For many, sport involves a form of physical change that provides mental and associated health benefits. The emphasis on physical elements to characterise sport is evident in much of the literature on sport entrepreneurship although there is increasing emphasis on the electronic forms of sport that have changed the industry structure. The sport industry has unique features that differentiate it from other industries including "the uncertainty of outcomes, the desire for competitive balance, the product (instead of market) led focus, cooperation across teams and organizations, a lack of control over the product, a focus on performance over other outcomes (e.g. return on investment), the fans as both producers and consumers, and the interdependent relationship with the media" (Cunningham et al, 2019:2). These unique features shape the competitiveness of the sport industry and make it an interesting industry to study. Another distinct feature is that there are different ways people engage with the sport industry from participating as an athlete or consumer to viewing it as a form of entertainment. This diversity has resulted in the sport industry attracting entrepreneurs due to low barriers to entry and the ability to make either a financial or societal difference. Some parts of the sport industry can be hard to enter due to the institutional structures governing the selling and making of merchandise. This is the case in professional 
sport leagues that are governed by certain rules and regulations. Formal institutions are defined as "the rules, regulations and laws and supporting apparatuses that establish order tin an economic, legal and political framework" (Skokic and Morrison, 2011:159). Sport needs formal institutions in order to monitor games and provide a sense of commonality. Informal institutions can be defined as "the norms, beliefs, values and similar conventions that form socio-cultural relations within a society" (Skokic and Morrison, 2011:159). The institutional institutions also play a large part in the way sport is viewed in society due to its bonding and reputation effect (Koronios, Kriemadis, Dimitropoulos and Papadopoulos, 2019). As is similar in other industries, there are portfolio and serial entrepreneurs in sport (Miragaia, Da Costa and Ratten, 2018). Depending on the success of their business idea, sport entrepreneurs can continue to innovate through creating new businesses that rely on the same idea. In order to do this, a sport entrepreneur needs to assess the desirability and feasibility of their business venture (Ratten, 2011).

Entrepreneurship and management scholars have been paying greater attention to the creativity in the fitness industry, particularly in terms of new business ventures. The fitness industry is defined as "a monolithic term used to describe a sector in the sport industry that comprises such disparate businesses as chain health clubs, supplement companies, personal trainers, clothing and shoe manufacturers, MMA gyms, CrossFit gyms, niche gym, magazine and internet media and equipment manufacturers" (Hemme et al, 2017:93). This definition acknowledges the wide variety of businesses in the fitness industry and the large market appeal they have in the global economy.

The structure of this paper is as follows. Firstly, the process of sport entrepreneurship will be explained in terms of how it works in society and its importance in entrepreneurial ecosystems. Next, the role of digital transformation for the sport industry is explained in terms of knowledge management and sport entrepreneurship. This leads to a discussion of 
sport and value co-creation with a focus on strategy as a practice. Lastly, managerial implications and future research suggestions are stated.

\section{Process of sport entrepreneurship}

An individual is considered an entrepreneur when they have undertaken some kind of action in an innovative and risk-taking manner. This means an entrepreneur is involved in discovering new things through a process of creativity and innovation. Societies that have a strong entrepreneurial culture normally view entrepreneurs as heroes (Jones, Ratten, Klapper and Fayolle, 2019). This means there is a mythology of entrepreneurs being regarded in an almost superpower way as they act as change agents. An entrepreneur needs to have some perseverance in terms of discovering new opportunities in order to be considered successful (Van Praag, 1999). Entrepreneurs engage in entrepreneurship when they develop an idea into a commercial reality. Entrepreneurship broadly defined involves "the recognition and exploitation of opportunities" (De Carolis and Saparito, 2006:41). Entrepreneurship is necessary to the functioning of any economy due to the way it enables new ideas to enter the marketplace (Ratten and Welpe, 2011). Competitiveness and innovation are topics linked to entrepreneurship and they are emphasized by public policy planners. This is due to sport organisations decreasing their reliance on government funding by looking at ways to foster entrepreneurship both from a new venture perspective but also through existing businesses. This has meant entrepreneurship is a topic actively pursued by sport public policy planners in order to obtain better results (Miragaia, Ferreira and Ratten, 2017).

Research in entrepreneurship has attracted more attention from sport management scholars. This is due to most of the existing studies on sport entrepreneurship viewing it as a deliberate strategy and as an intended way to be competitive (Ratten, 2012). Thus sport organisations 
deliberately engage in entrepreneurial behaviour as a way to stay competitive. Whilst there are other environmental factors that influence the entrepreneurial capabilities of a sport organisation, the most important driver of entrepreneurship is to stay ahead of the competition.

Sport entrepreneurship can be viewed at an individual, organisational or relational level. Most studies tend to focus on organisations as there is a plethora of examples of sport entities being entrepreneurial. At the individual level, the way athletes, coaches and managers are entrepreneurial has been studied but not in a substantial way. This means there is a gap in the literature in terms of understanding how the sport context influences motivates an individual to be entrepreneurs. Even less studied is the relational level as it is hard to obtain data about how entities collaborate with or between themselves. The relational level implies the use of networks however this is not fully explained in the current sport entrepreneurship literature.

All type of sport entrepreneurship involves some degree of risk, which refers to the willingness to do something when there is a cost of failing. By committing more time or resources to an action, an individual is involved in some form of risk taking. In the highly volatile and dynamic international business environment, some degree of risk taking is needed. Whilst many outcomes are unknown, some can be assessed in terms of probability of occurring. This helps to assess the degree of uncertainty associated with an action in sport. This is important as to be competitive means to look at things in a different way in order to obtain enhanced results.

Sport experiences often extend beyond the initial consumption to include other forms of emotional attachment and purchasing behaviour. Thus, when analysing a sport experience, the prior, during and after phase is also important. Prior to sport experiences consumers will research and find out information relating to the event. This form of homework is an 
important precursor to the actual sport experience. During the sport experience consumers will also interact with other media channels depending on their preferences such as social media. In addition, they will consume food and drink or purchase other material related to sport. After the sport experience, the consumer will then turn to other media devices in order to relive the experience or alternatively compare it to future events. The discovery and deployment of entrepreneurial opportunities is essential in all forms of sport but particularly professional sport, which can be described as "a hyper-competitive environment, which produces constant pressures on organisations to discover and exploit new opportunities to survive, grow and win competition" (Radaelli et al, 2017:1). This means any new ideas or ways to increase performance will be extremely valued by the sport industry.

\section{Sport entrepreneurship and ecosystems}

The essential significance of sport entrepreneurship lies in five main points. First, the sport industry operates as an ecosystem with interactive network members disseminating information. This enables innovation to develop as it is discussed amongst members of the ecosystem. There are positives and negatives about sport entrepreneurship so information is required in order to make decisions. This means a time delay exists between coming up with an idea then that idea entering the marketplace due to the need to consult different people. In addition, there can be coopetition amongst sport entities in terms of competition but also collaboration. Second, each sport entrepreneur has their own views about how the entrepreneurship process should be managed. This can result in conflicting views about how to progress a business venture. Each sport entrepreneur needs to be considered on their own merits then evaluated accordingly. This enables the uniqueness of sport to be taken into account as a way of further distinguishing the sport industry. In addition, the process of sport 
entrepreneurship will change depending on where they are positioned in the industry. For early sport innovators that are making big changes to the industry they might be innovating in a quicker manner. This means disruptive changes occur as the sport industry significantly changes as a result of the innovation. Thus, the behaviour of the sport entrepreneur needs to be analysed in terms of their innovativeness. Third, the process of sport entrepreneurship is fluid and dynamic. This means there is no single formula to explain the success or failure of a sport entrepreneur. Rather it depends on the context and ability of a sport entrepreneur to navigate the business environment. Sport entrepreneurship incorporates both profit and nonprofit motives so they need to be considered in terms of available opportunities. Fourth, sport entrepreneurship should be considered from a number of different perspectives including both the physical and digital forms. Traditionally the use of new sport clothing or equipment was highly visible and this meant most sport entrepreneurship was viewed in this way. However, entrepreneurial financing such as crowdfunding and the use of hybrid equity has become more popular. The sport industry uses a lot of public/private partnerships so these kinds of collaborative agreements can be entrepreneurial in nature. Moreover, as the sport industry is distinct with its use of community, amateur and professional leagues there can be further innovative practices. This makes the sport industry in terms of structure very interesting to study from an entrepreneurship point of view. Fifth, the government has a major influence on sport entrepreneurship. This means for entrepreneurial purposes the government is more likely to be either indirectly or directly involved in the decision making processes. However, the process of sport entrepreneurship remains elusive since it requires the sharing of information with stakeholders an ecosystem environment.

Stakeholders are entities whose support is needed for an organisation's existence. In order to progress, an organisation needs to consider its stakeholders and how their participation can lead to increased value creation (Freeman, 1994). To do this an understanding about the 
actual or potential harms that a stakeholder experiences as a result of a sport organisations actions is required. This includes considering the ways in which stakeholders are impacted by an organisation. Stakeholders interact with sport organisations in a variety of ways, and these relationships influence organisational practice. Stakeholders can also include the media, policy, the general public and other entities that form part of a community. Some stakeholders in a sport ecosystem will be more important than others depending on their position in a network. This means stakeholders with greater levels of social ties in a community are considered as having more in-degree centrality in a network. This results in more paths connecting them with others in a network. However, networks vary in size so the number of stakeholders in an entrepreneurial ecosystem needs to be considered.

Within an entrepreneurial ecosystem are the stand up, start up and scale up stages (Autio et al, 2018). The stand up stage involves testing ideas through "hackathons, innovation challenges, talent scouting, speed dating events, networking events, entrepreneurship programs" (Autio et al, 2018:84). Each of these different types of events provides a way for information about new ideas to be disseminated to others. This is important in spreading knowledge about potentially useful ideas (Al-Salti and Hackney, 2011). Although part of this process also involves motivating others about lucrative possibilities. Entrepreneurs are part of this motivational process as they develop concepts then identify ways to get them into the marketplace. Networks are a way for entrepreneurs to obtain help from others in order to test new venture concepts.

The start-up phase involves "accelerators, coworking spaces, makerspaces, networking events, start-up academies, crowdfunding, angel investors" (Autio et al, 2018:84). The start up stage progresses an idea from an initial thought to a potential business venture. The mechanisms for shifting ideas into actual business ventures involves cultivating knowledge around potential market entry (Jashapara, 2010). This involves experimenting with business 
models to see what works and how it can be progressed in the marketplace. By disseminating information about potential sport business ideas a process of team building takes place. This enables the initial ideas to be pursued.

The scale up stage involves "business angels, crowdfunding, venture capital, mentoring initiatives" (Autio et al, 2018:84). Once an initial idea has moved through the stand-up and start-up phases it then needs to be progressed into the marketplace. To do this involves resources and the supply of capital in the form of money or time. Depending on the nature of the sport business venture, the resources may also include physical and human capital. Thus, to scale-up a business idea help from others in the form of infrastructure or venture financing is required. Each of these stages of the entrepreneurial ecosystem are being affected by the digital transformation occurring in the global economy. Therefore, this leads to the first research proposition:

Research proposition 1: Sport, fitness and lifestyle entrepreneurship needs to be understood through an entrepreneurial ecosystem perspective focusing on the stand up, start up and scale up stage.

\section{Digital transformation of the global economy}

The change in the global economy from manufacturing orientated to knowledge and service orientated has resulted in a shift towards viewing the consumer and producer relationship as being a co-creation process (Vargo et al, 2008). This has influenced the way sport services are marketed and consumed in the marketplace. The sport industry is changing from being manufacturing based to digitally orientated as information and communications technology is integrated into everyday business activity. Previous industrial revolutions focused on computerization, electrification and mechanization, whilst the current industrial revolution is 
centred around digitalization (Dalmarco et al, 2019). In order to succeed in the global marketplace, it is becoming critical that sport businesses utilise digital technology effectively. Digital transformation refers to "the transformational or disruptive implications of digital technologies for businesses (new business models, new types of products/services, new types of customer experiences)" (Nambisan et al, 2019:1). In response to digitalization sport organisations have been radically changing their business strategies to incorporate more digital infrastructures and platforms. This has meant a restructure of the way many sport businesses are viewed in the market and a redefinition of what being an entrepreneurial sport business means.

The advantage of digitalization is in accessibility of information, but this results in privacy and security concerns for users. Thus, information needs to be protected in an online format and this is resulting in new business ideas emerging in the marketplace (Santoro, Vrontis, Thrassou and Dezi, 2018). The anonymity of users accessing data can be a hard task and this has created new businesses that target this issue. In addition, there needs to be trust in the data provider to ensure repeat usage. Digital technologies have fuelled innovative initiatives that have resulted in the creation of new firms (Lusch and Nambisan, 2015). This has meant our understanding of innovation has changed as a result of digitalization from innovation and its impact on the process of change.

The pursuit of innovation is a common theme running through the sport entrepreneurship field. This is due to the traditional view of sport entrepreneurship being a corporate endeavour that is orientated towards large scale developments. This stereotype suggests that firms are the main instigators of sport entrepreneurship as they strive to have a market advantage. This view has changed with the realization sport entrepreneurs can be individuals in small firms and community-based organisations. In addition, as sport for social change has gained recognition there is a change in the way sport entrepreneurship relies on the dynamic 
interplay amongst a group of entities. This means there is often a collective social goal in sport enterprises to work together to achieve entrepreneurial outcomes. Thus, the notion of social learning and collaboration is at the heart of sport entrepreneurship.

Sport innovations are interventions initiated by sport actors to offer a solution to a problem. This means meeting specific needs by taking advantage of an opportunity. The main tools needed for innovation are inspiration, ideation and implementation (Brown and Katz, 2011). Inspiration involves having an idea that motivates a person to act in a certain way. People get inspiration from a variety of sources that feeds their passion for entrepreneurship. Ideation is the process of coming up with an idea then seeing it progress into a sport business venture. Some testing of ideas is needed in this stage in order to access the sport market potential. Implementation is acting on the idea so that it is progressed in the market. The usage of innovation in sport has varied with resource-rich professional clubs being able to adopt technological change at a faster rate than less resource endowed clubs. Therefore, the management of innovation in sport is also an issue as it can be a complex process.

Innovation and entrepreneurship play a crucial role in sport business as a result of many technology changes taking place in the global business environment. The creation of new products, services and technologies are required in sport business due to competitiveness reasons. This means the range of innovativeness in the sport industry can vary from incremental to radical depending on the nature of the change. When combined with technological advancements, the innovation can be even more profound. Thus, it is timely to discuss the way innovation develops in a sport context in order to understand contextual changes in the industry.

Organisations adopt innovations based on considerations of their relative advantage, compatibility, complexity, trialability and observability (Rogers, 2003). Relative advantage 
means the innovation has some benefits over existing procedures that make it more attractive. Sport organizations will perceive this advantage as providing additional benefits. The advantage can take the form of economic, social prestige and satisfaction. Economic advantage means there is a financial gain to be made from implementing the innovation. Financial considerations are paramount for sport organisations who need to manage their monetary resources. Whilst saving money might not be needed in some rich sport clubs, for amateur and community sport club's sustainability of resources is an important consideration. Compatibility means that the innovation can be used with other products or services in a sport organisation. Complexity refers to innovation be implemented. If the innovation is of a radical nature, then it can result in big changes to an organisation. Incremental or smaller scale innovations are less complex to incorporate within an organisation's existing structure. Trialability refers to seeing how the innovation works and whether it will provide a positive benefit. This includes testing new ways of using the innovation to see which is the best approach. Observability refers to watching how the innovation progresses and what people think about this. Some sport organisations have a wait and see approach in order to understand the ways an innovation can be fully utilised as a result of emerging technology.

Schot and Geels (2008:537) refer to new technologies as hopeful monstrosities as "they are 'hopeful' because product champions believe in a promising future, but 'monstrous' because they perform crudely". This is an interesting analogy as normally new technologies are referred to in a glowing manner. The reason behind calling new technologies hopeful is that often at the time of invention it is unknown how successful they will be in the marketplace. A new technology involves the use of flexible internet-based production systems, which has also been referred to as the internet of things. The integration of web-based systems into sport businesses has altered the way innovation is developed. Some technologies are rapidly adopted in the market whilst others take a long time to gain recognition. This means whilst 
some sport entrepreneurs or inventors have a gut instinct for knowing whether a technology will have an impact, other technologies need to be tried and tested in the market. Due to the need to be a first mover in the market often digital technologies are introduced quickly into the marketplace. This has meant technology changing the sport industry and influenced the competitiveness of sport organisations. Technology is being diffused throughout the sport industry and being used as a strategic advantage. The impacts of technology are evident in many different ways in the sport industry from system processing to marketing functions. Most of the changes from technological innovation have resulted in more efficient production systems. Although some processes have also been redesigned to make them more consumer friendly. This is due to customers wanting more self-service technology. In addition, there is more co-creation between consumers and sport organisations due to the technological paradigm shifts.

Initially more sports were reluctant users of technology due to the need to compare current performances with past records. With the advent of the internet, the sport industry gradually introduced more technology services. The growth of mobile apps on phones further changed the sport industry and was a source of innovation. This is due to technological disruptions such as enhanced analytical capabilities, the internet of things and rich media are transforming society (Buhalis et al, 2019). The sport industry has been a major recipient of these technological disruptions, with artificial intelligence and virtual reality further set to change current business practices.

New sports like esports are further changing the way sport is consumed. This has resulted in traditional ways of measuring and analysing sport changing to reflect societal advancements. Artificial intelligence is making shifts in the way technology is used in a sport context. Experimenting with technological advances such as robotics and augmented reality are providing interesting developments to the sport industry. Virtual reality has further 
transformed the way people see sport and an increased use of this kind of technology is being used. In response to changing fan, athlete and consumer expectations there has been greater integration of technology within sport. Data analytics are being used as a way to track changes and respond to needs. However, despite the plethora of positive examples of sport technology there are varying levels of success attributed to innovation. This is due to sport entrepreneurship and innovation giving rise to both challenges and opportunities depending on one's perspective.

In order to stay competitive, more businesses are trying to generate new ideas and processes that incorporate some form of internet capabilities. This includes cyber-physical systems that blend the way humans and the internet interact. Whilst this opens up opportunities for business, there are still developments that are needed in internet connectivity and the use of digital technology.

Entrepreneurs have had to rethink their business practices in order to incorporate novel digital innovations. This has led to managerial implications in terms of the processes and outcomes used to assess entrepreneurship. The digital marketplace involves selling or consuming things in an online context. To do this there needs to be the online participation of different stakeholders such as commerce, education, government and health providers (Song, 2019). Similar to a physical marketplace, the digital one requires regulation and governance mechanisms in order to operate effectively. This involves making sure transactions are conducted in an ethical and appropriate manner. Increasingly users in digital marketplaces are becoming concerned about privacy rights due to the amount of information shared online. This has resulted in much media attention about the rights on online users and how to safeguard their privacy. An online context can provide more accessibility to users as it can be accessed at any time or geographic location. 
Digital user citizenship incorporates the community of users who are involved in online activities (Song, 2019). As more individuals, businesses and other entities utilise online commerce platforms, they have created a sense of community. This is regulated by the rules of the internet and associated relational norms. Much of this change is the result of Industry 4.0 which is conceptualised as "the integration of different technologies into an autonomous, knowledge- and sensor-based self-regulating production system" (Dalmarco et al, 2019:1). The sport industry has been one of the most effected industries from industry 4.0 due to the increased usage of technology in sport, which has meant more interest in how to manage knowledge in sport for entrepreneurial gain. Therefore, this leads to the second research proposition:

Research proposition 2: Sport entrepreneurship needs to incorporate more emphasis on digital transformation especially that from technological innovation and artificial intelligence.

\section{Knowledge management and sport entrepreneurship}

The sport industry is already one of the most innovative and entrepreneurial industries in the world. It has done this by learning from other industries and imitating best practices. By capturing new knowledge, it has been able to innovate in a variety of different ways. Guided by a technology innovation strategy, the next step for the sport industry will be to consolidate innovations and then further progress its competitiveness. The sport industry is now considered a knowledge intensive industry due to its emphasis on technology development but in order to be truly entrepreneurial sport organisations need to have an absorptive capacity.

Absorptive capacity refers to an organisations ability to learn from others (Lazzarotti et al, 2015). The main steps involved in having an absorptive capacity in an organisation are 
recognizing valuable knowledge, learning form the knowledge and creating new knowledge (Lane et al, 2006). These steps help an organisation utilise external knowledge in a beneficial way. The ability to assess whether knowledge is valuable can be a complex process due to some exploration about the knowledge being needed (Perez-Lopez and Alegre, 2012). Knowledge can take a variety of different forms so it is important to assess whether it can lead to new innovation. To do this transformational learning is required in terms of significantly shifting existing learning patterns. This means focusing on the possible commercial outputs related to the knowledge. Absorptive capacity is normally assessed through research and development metrics in terms of how innovation has led to commercial ventures. However, some forms of absorptive capacity can be difficult to assess due to the level of intellectual capital involved.

In the initial definition of absorptive capacity three main steps of using knowledge were identified: recognition, assimilation and commercialization (Cohen and Levinthal, 1990). The ability to recognise the value of knowledge can be difficult when it is hard to assess how it can be used. If the knowledge is similar to existing forms of knowledge it might be easier to do this. Thus, the type of new external knowledge needs to be compared and contrasted to existing knowledge sources. The ability to assimilate knowledge is a skill that can take years to refine. Some organisations are more skilled at this than others due to their willingness to use new knowledge. Other organisations might take a wait and see approach to see how it is being used in other contexts. The ability to commercialise knowledge is important in terms of gaining financial respectability in the marketplace. Commercialisation of innovations is an important way to assess their marketability through the adoption by consumers.

Zahra and George (2002) further progressed the concept of absorptive capacity by dividing the ability to assimilate knowledge into two sub-components: understanding knowledge and transformability. The ability to understand knowledge comes from a capacity to know what is 
useful. This skill can take time to develop as it specifies routines are needed to change knowledge into an outcome. Transformability involves converting the knowledge into new opportunities. This involves a process of entrepreneurship as the knowledge needs to turn into innovation. Some knowledge has potential, but it may take some time to develop. Thus, realized forms of knowledge are more useful as their output is already known in the marketplace.

In today's business environment, sport entrepreneurship has become increasingly knowledge intensive. Considering the important role that sport plays in the economy, it is interesting to investigate how entrepreneurship is used in sport in order to increase efficiencies. As modern sport management spans numerous entities from athletes, managers, service providers, retailers, fans and customers, it is promising to study what entrepreneurship means for the sport industry. An enhanced ability to respond to emerging technology as well as to improve skills is expected to improve the quality of sport services. By applying cutting-edge technology to sport there will be an advancement in the services provided. Knowledge management is required in sport in order to handle the continuing flow of information provided to different sport entities.

Knowledge management is defined as "a specific, systematic and organizational process, to create, transfer, integrate and leverage the associated knowledge, that knowledge of a particular functional unit is applied across other functional units that differ in competitive advantage" (Chuang, Liao and Lin, 2013:218). Knowledge is critical in any industry but particularly in sport due to the need for timely communications. This means the ability of sport enterprises to recognise then distribute knowledge is important. Knowledge is obtained from various sources both within and outside the sport industry. 
Durst and Evangelista (2018:428) defines knowledge management processes as "a set of practices that individuals and teams use in order to create, store, transfer and use knowledge in the most effective way". In order for knowledge to provide value it needs to be acquired, shared and then applied (Gold et al, 2001). For sport organisation's the use of knowledge helps them improve their competitiveness by updating or replacing existing knowledge sources.

A knowledge management strategy can create and sustain value in sport. Social networks help with the acquisition of knowledge by enabling individuals to access information from different sources. The successful integration of knowledge requires the commitment of leaders and support from management. This ensures knowledge management systems and tools can be used in sport business. A knowledge map can be constructed as a way to understand the flows of knowledge.

Few studies have been conducted on the intersection between sport entrepreneurship and knowledge management. Bacon et al (2019:3) states "knowledge is often typified as information-based and codifiable (explicit) or experience-based and personal (tacit)". Both types of knowledge are needed in sport in order to accelerate the entrepreneurship process. Explicit knowledge can be easier to transfer as it is in a written format (Nonaka and Takeuchi, 1995). Coaches often write down their game strategies and this is a form of explicit knowledge. Other examples might include data analytics and information obtained through statistical modelling. Tacit knowledge is harder to transfer as it involves experiences and intellectual capital. In addition, some forms of tacit knowledge are difficult to explain. Causal ambiguity is a way of understanding the knowledge transfer process. Bacon et al (2019:3) defines causal ambiguity as " $a$ lack of clarity regarding the origins and components of knowledge". This means the credibility of knowledge can be questioned unless the source is known. In order to assess the trustworthiness of the knowledge provider there needs to be 
some verification about where and how the knowledge was obtained. Being able to trust another person is an important enabler of knowledge transfer (Thomason et al, 2013). This is due to repeated interactions and cooperative behaviour providing a sense of respect.

Explicit knowledge is transmitted via systemic language modes that enable individuals to interpret the data. Tacit knowledge includes expertise, intuition, job experience, know-how, memories, sills and working solutions (Scaringella and Burtschell, 2017). Explicit knowledge includes documents, process diagrams, project reports, patents, manuals and memos (Scaringella and Burtschell, 2017). Both explicit and tacit knowledge are used in sport entrepreneurship. This is due to knowledge being required to develop entrepreneurial capabilities in sport organisations.

The key outcomes of knowledge management are creation, retention and transfer (Ordanini et al, 2008). Knowledge creation involves making knowledge in a way that has not been done before. For sport organisation's knowledge creation can be conducted in different ways including through both planned and unplanned actions. Knowledge retention involves keeping knowledge that is acquired from other sources. Due to the amount of knowledge available in sport, it can be hard to sort out what type of knowledge should be obtained. Cloud computing and other data storage systems have made this easier to do but it still is hard to sort out what knowledge is potentially useful. In addition, sport knowledge can come in a variety of different forms including statistics so it might need an export to interpret the data. Knowledge transfer involves sharing the knowledge to another entity. This can be conducted in an express manner when the importance of the knowledge is known. However, unplanned transfer can also occur in the form of knowledge spillovers, so it is useful to understand the ways knowledge is transferred in a sport context. For sport organisations, they need to: 1) invest in the acquisition of knowledge, 2) reward people who use knowledge for entrepreneurial purposes, 3) make efforts to store knowledge, 4) endeavour to learn better 
how to use knowledge and 5) carry out new entrepreneurial activities based on the sharing of knowledge.

Knowledge transfer comprises four main steps: socialization, externalization, combination and internalization (Nonaka and Takeuchi, 1995). Socialization involves disseminating knowledge so that others can learn about its usefulness. This involves discussing what the knowledge means and its potential benefits. The process of socialization can include different communication mechanisms such as face-to-face interactions or online exchanges.

Externalization involves changing the form of knowledge from tacit to explicit. This involves codifying knowledge in a format that others can understand. Different mechanisms to do this include writing it down and providing comments on its meaning. It is important to communicate knowledge to others otherwise it can be lost. This means it can be useful to have a policy in terms of how knowledge is recorded (Jansen et al, 2005). This enables knowledge competences to be developed that can facilitation further collaboration (Shafia et al, 2011).

Combination involves the use of aggregated knowledge from multiple sources. To successfully combine knowledge, it can be useful to use knowledge management tools. Internalization involves learning from knowledge sharing in order to conduct new tasks. The knowledge funnel process can be used as a way of exploring different ideas used to come up with an innovation (Steinmueller, 2000). The main steps of the knowledge funnel are: pinpointing a market opportunity, devising a solution and codifying its operations (Martin, 2010). To pinpoint a market opportunity means finding a specific issue to be solved. This means clearly defining what the opportunity is and its impact on the marketplace. Devising an offering involves finding a way to see the market that can be achieved through a quick process. Codifying its operations means replicating the system in another context through a process of organisational learning. 
Organisational learning comprises four main processes: intuiting, interpreting, integrating and institutionalising (Crossan et al, 1999). These processes are interconnected and develop over a period of time. Zeimers et al (2019:83) states "intuiting and interpreting take place at the individual level, while integration occurs at the group level, and institutionalisation at the organisational level". Thus, each stage of the organisational learning process needs the involvement of individuals, groups and organisations. This multi-level approach means that it can sometimes be hard to coordinate the process of learning. Intuition involves recognising something based on an internal reaction. Some people are more intuitive than others and this reflects what kind of information they are willing to receive. Intuition is an important skill that needs to be valued by individuals. The thought processes involved in intuition mean sending a thought or behaviour occurring from an action. This means individuals who act on their intuition are likely to be more confident in following their intuition in the future. Intuition can be further distinguished in terms of entrepreneurial or expert (Zeimers et al, 2019). The development of intuition can be useful in sport entrepreneurship through a process of value co-creation. Therefore, this leads to the third research proposition:

Research proposition 3: Sport entrepreneurship research and practice needs to incorporate a knowledge-based view that emphasises organizational absorptive capacity.

\section{Sport and value co-creation}

Holbrook (1999:9) describes value as something that "resides not in the product purchased, not in the brand chosen, not in the object possessed, but rather in the consumption experience(s) derived therefrom". This definition emphasises the experience rather than the product or brand. However, the importance placed on the experience can be debated due to the amount of fan loyalty existing in a sport context. Fans religiously attend games or buy 
products based on their allegiance to a sports team. Thus, they can attend sport events because of this habit, and this can involve wanting to feel part of the sport experience.

Value co-creation plays an indispensable role in sport entrepreneurship. This is due to the process of co-creation enabling feedback from customers and users to be incorporated in the design of new services (Edvardsson et al, 2011). Co-creation can be defined as "joint collaborative activity by parties involved in direct interactions, aiming to contribute to the value that emerges for one or both parties" (Gronroos, 2012:1523). There has been a realization by sport organisations that co-creation enables better innovative outcomes. By incorporating knowledge from multiple sources, it allows firms to improve their value propositions. This enables the use of customer operational knowledge that can be supplemented by new process technology.

Value co-creation can be described as "value creating activities that result in the production of products they eventually consumer and that become their consumption experience" (Xie, Bagozzi and Troye, 2008:110). Compared to the past when there was an arms length agreement between consumers and producers, value co-creation involves consumers and producers collaborating on products and services (Yi and Gong, 2018). The new approach is based on social exchange theory, which emphasises the benefits of collaboration. Assiouras et al (2019:3) states "the core theoretical assumption of social exchange theory is that all social life can be investigated as an exchange of tangible and intangible rewards and resources between/among actors". This is useful in a sport entrepreneurship context that has an inherent social component due to repeat interactions with multiple stakeholders.

Co-creation refers to a collaboration process based on joint input and feedback. As it is easier for consumers to access and obtain information, they are wanting to become more involved with the development of products and services. To do this consumers are being empowered to 
suggest ideas that change how things are currently conducted. This means changing the status quo in order to experiment with more efficient and effective methods. Data driven means that decisions are influenced by statistics and analytics. This includes data about a person's tastes and preferences is important. Data helps consumers obtain more personalised services based on their preferred preferences. In the highly competitive marketplace, the use of data can make a difference to what services or products are consumed. Thus, businesses need to be able to use data in a way that provides the best services to consumers. This includes having dynamic pricing based on seasonal events based on real-time information.

Real-time marketing has been defined in various ways but common to most definitions in the emphasis on current behaviour that can benefit from timely feedback. For this reason, the concept of real-time marketing has gained ascendancy in the literature as a way to provide relevant and personalised services. This is important as more consumers expect information that is based on their location and personal history. This means marketing that is automated and reflects their preferences is more valued. To properly use real-time marketing there needs to be instant interaction based on consumer's actions and behaviours. This results in targeting the marketing based on data or events that are occurring in the environment.

Buhalis and Sinarta (2019) suggest that there are five core characteristics of real time cocreation: real-time, co-creation, data-driven, consumer centric and experience enhancement. Real time refers to immediate reactions that are not delayed. Due to the increased usage of mobile communications in sport more people are expecting instant replies. This has changed the sport marketplace into a more dynamic one that emphasises direct interaction. Real time can refer to online or offline interactions, but the emphasis is on direct communication with consumers. 
Consumer-centric means that services are based on fulfilling the needs of consumers. This includes focusing on customer intelligence in terms of previous interactions and buying behaviour. To do this it is useful to predict behaviour based on statistical modelling and data analytics. Sport consumers are using their social networks in determining what to buy so the use of social profiles is also important. Experience enhancement means adjusting services to suit a customer's requirements. This includes changing the way sport services are consumed in order to provide a more tailored experience. As sport consumers increasingly want quick,

reliable and personalised services this is an important component of the consumer experience. In addition, expectations about service quality and standards need to be managed in order to create entrepreneurial opportunities. Thus, this leads to the fourth research proposition:

Research proposition 4: Value creation in sport is the result of social networks, experience and personalisation.

\section{Sport entrepreneurship and strategy}

The strategy as a practice perspective focuses on the implementation of ideas and plans rather than just theorizing about future directions (Tidstrom and Rajala, 2016). Johnson et al (2007:7) define strategy as practice as "a concern with what people do in relation to strategy and how this is influenced by and influences their organisational and institutional context". This means strategy practices can be viewed as a continual process designed to increase performance. In the sport industry, strategies are subject to change depending on the environmental context. Strategies can be short or long term orientated depending on the reason for their existence (Chia and Mackay, 2007). Some strategies start in a temporary format then become more entrenched as time progresses. This means strategies can be adapted to suit the sport market environment (Dahl, Kock and Lundgren, 2016). Strategies 
that are flexible in nature are able to adjust to changing trends. This enables rapid changes to take place if needed. However, cultural and historical conditions influence the development of a strategy (Chia and Holt, 2006). This is particularly relevant in the sport industry that prides itself with being innovative but also respectful of traditions.

Within the strategy as a practice perspective there is an acknowledgement that cooperation and competition are both integral to the global economy. This is referred to as coopetition as individuals and sport organisations need to collaborate but at the same time compete with each other. Bengtsson (2010: 200) defines coopetition as "a process based upon simultaneous and mutual cooperative and competitive interactions between two or more actors at any level of analysis (whether individual, organization or other entities)". Sport business relationships evolve over time, so it is important to understand the reasons why they change. Some of the changes can be attributed to economic forces but other reasons might be of a more personal nature. Thus, the dynamics of business relationships need to be analysed in terms of the past, present and future. Each different time period influences the development of a business relationship in a different way. This means there is an interplay between current and historical events that influence coopetitive business relationships.

Tidstrom and Rajala (2016) suggest that coopetition strategy goes through four main stages: pre-coopetition, silent coopetition, active coopetition and forced coopetition. In the precoopetition stage, there is an awareness of the need to collaborate with competitors due to market dynamics. The dialogue between entities in this phase is of a functional nature in terms of understanding what joint tasks are needed. In the silent coopetition phase, there is an active participation in collaboration but uncertainty as to how this will evolve. There is pressure on obtaining more knowledge about the collaboration process in terms of potential benefits. This involves creating new ways of working in a team that encourages sport innovation. The active coopetition phase involves proactively engaging in joint sport-related 
projects. This means sharing information about new ideas that will lead to mutual gain. The forced coopetition phase means there is a need to collaborate because of existing projects but there is a duty by the partners to go in new directions. This means there is decreased interaction resulting from the change in routines, which may require some design thinking to be used.

There are three main methods to design thinking: needfinding, brainstorming and prototyping (Seidel and Fixon, 2013). Design thinking is derived from the creative industries compared to the more rational approaches from the mathematical and science field (Beckman and Barry, 2007). In the sport management and engineering fields there has been a more scientific approach to innovation, but this has changed with more people using design thinking due to its flexible nature. Needfinding involves trying to find problems that can be solved through the introduction of a sport innovation. Sport businesses have different needs and these are changing as a result of technological innovation. Thus, in order to find certain needs there should be an assessment of what is currently in the market. This can involve drawing on existing technologies then predicting what needs to change. To do this requires some time as the needs should be carefully considered then thought about in terms of current capabilities. By taking an empathetic approach more insights into user needs can be identified. This is important in gaining a improved understanding of how and why people need certain things. By actively immersing oneself in the experience of a person having a certain need it can lead to better innovations developing. Through experience the circumstances from a first-hand perspective, the design thinking should be more authentic. This is important in providing clarity about what is expected and the experience people have. In addition, need finding is important in understanding the urgency of certain needs.

Brainstorming involves thinking about numerous ideas that are both related and unrelated to a solution. This process enables people to think outside the box as a way to derive new sport 
solutions. In a group setting, brainstorming enables others to build on ideas. Design thinking incorporates reflexive practice as it provides a way for individuals to think in a creative manner. This is useful in combining artistic knowledge that is often used in the creative industries with technical knowledge. This combination can enable more analytical reasoning as it enables different thought methods from a logical and creative perspective to be used. Prototyping means then testing the sport innovation in the marketplace and if needed making alterations. Therefore, this leads to the fifth research proposition:

Research proposition 5: Strategic planning and design thinking are needed in sport entrepreneurship in order to facilitate more creativity.

\section{Future research directions}

The research propositions discussed in the previous section highlight the importance of taking into account the way digital technology has transformed the sport industry. This means there are numerous opportunities for future research to take that embeds a knowledge management and digital disruption approach. Much of the research in the field of sport entrepreneurship has a relatively short history but has risen in prominence in recent years. Sport entrepreneurship refers to profit and non-profit activity undertaken in an economic way. In order to make meaningful connections from the sport to the lifestyle entrepreneurship area, there needs to be more distinctive theories that take a holistic perspective about what sport means in society. Whilst it is evident in practice the importance of innovation and entrepreneurship to sport, there is still a lack of research on this topic. This means it is imperative that research describing the innovation and entrepreneurship process from a sports view be conducted. This will help to clarify the way sport clubs are using innovation and the way entrepreneurial ecosystems are developing. Current research has revealed little about the 
interlinkages and context of innovation in sport nor contrasted it to other industries.

Therefore, future research needs to address the following research question:

Research question 1: How does context influence the rate of innovation and entrepreneurship occurring in the sport industry?

More research is focusing on sport entrepreneurship due to the increased emphasis on health and lifestyle initiatives in society. People are living longer and there is more emphasis on work/life balance. This has resulted in more sport, fitness and lifestyle businesses emerging in the global economy. Despite the practical linkages between sport, fitness and lifestyle entrepreneurship, the academic literature has been slower to incorporate these topics. This is surprising given the amount of money spent on sport, fitness and lifestyle initiatives.

The aim of this paper is to take a progressive view of the topic of sport entrepreneurship in order to synthesize existing research and move the field forward into previously unknown territories. By focusing on the role of digital transformation in sport the paper has moved the literature on sport entrepreneurship to a new area that focuses on knowledge management and value co-creation. This will enable better strategies about potential research topics to be derived that are interdisciplinary in nature but rely on entrepreneurship as their foundation. The future is exciting for sport entrepreneurship research so it is our hope that more researchers focus on this interesting and novel area of study. Thus, the second research question is:

Research question 2: How is digital technology entrepreneurship changing the sport, lifestyle and fitness industry? 


\section{Conclusions}

This paper has several practical implications. First, sport ecosystem actors are encouraged to discuss business ventures and ideas in order to build entrepreneurial capacity. The specific aims and objectives of a sport enterprise can vary depending on the input they receive from members of the community. This means it is important for sport entrepreneurs to communicate to different people what their proposed idea is and how it fits into the existing industry. To do this it might be useful to discuss how the idea from a practical standpoint will progress in order to assess the potential help required. By clearly stating what is required in terms of resources and time it can help further the idea. Joint knowledge processing activities can be used in the form of co-creation in order to assess the intellectual capital of individuals from various sources. Due to the constant technological change in sport, value co-creation methods can help reduce uncertainty levels. The process of value co-creation is becoming more common in a sport context due to the joint efforts of individuals that have an interest in sport. As sport involves passion, it can help to explain in detail the requirements of a sport enterprise. Second, sport managers can analyse the progression of an idea during different life cycle stages. Sport managers take risks in innovating but need to do so in order to survive. Some sport managers have a higher level of entrepreneurial orientation due to the way they pursue innovation. Normally a greater level of innovation in sport will lead to an outperformance in the industry. To achieve this, sport managers need to introduce innovative thinking in order to address entrepreneurial opportunities. 


\section{References}

Al-Salti, Z. and Hackney, R. (2011) 'Factors impacting knowledge transfer success in information systems outsourcing', Journal of Enterprise Information Management, 24(5): 455-468.

Assiouras, I., Skourtis, G., Giannopoulos, A., Buhalis, D. and Koniordos, M. (2019) 'Value co-creation and customer citizenship behavior', Annals of Tourism Research, 78: 1-11.

Autio, E., Nambisan, S., Thomas, L. and Wright, M. (2018) 'Digital affordances, spatial affordances and the genesis of entrepreneurial ecosystems', Strategic Entrepreneurship Journal, 12: 72-95.

Bacon, E., Williams, M. and Davies, G. (2019) 'Recipes for success: Conditions for knowledge transfer across open innovation ecosystems', International Journal of Information Management, 59: 377-387.

Ball, S. (2005) 'The importance of entrepreneurship to hospitality, leisure, sport and tourism', Hospitality, Leisure, Sport and Tourism Network, 1(1): 1-14.

Beckman, S. and Barry, M. (2007) 'Innovation as a learning process: Embedding design thinking', California Management Review, 50(1): 25-56.

Bengtsson, M., Eriksson, J. and Wincent, J. (2010) 'Co-opetition dynamics- An outline for future inquiry'. Competitiveness Review: An International Journal, 20(2): 194-214.

Brown, T. and Katz, B. (2011) 'Change by design', Journal of Product Innovation Management, 28(3): 381-383.

Buhalis, D., Harwood, T., Bogicevic, V., Viglia, G., Beldona, S. and Hofacker, C. (2019) 'Technological disruptions in services: Lessons from tourism and hospitality', Journal of Service Management, 30(4): 484-506.

Buhalis, D. and Sinarta, Y. (2019) 'Real time co-creation and nowness service: Lessons from tourism and hospitality', Journal of Travel and Tourism Marketing, 36(5): 563-582.

Chia, R. and Holt, R. (2006)'Strategy as practical coping: A Heideggerian perspective', Organizational Studies, 27(5): 635-655.

Chia, R. and Mackay, B. (2007) 'Post-processual challenges for the emerging strategy-aspractice perspective: Discovering strategy in the logic of practice', Human Relations, 60(1): 217-242.

Chuang, S., Liao, C. and Lin, S. (2013) 'Determinants of knowledge management with information technology support impact on firm performance', Information Technology and Management, 14(3): 217-230.

Cohen, W. and Levinthal, D. (1990) 'Absorptive capacity: A new perspective on learning and innovation', Administrative Science Quarterly, 35(1): 128-152.

Crossan, M., Lane, H. and White, R. (1999) 'An organizational learning framework: From intuition to institution', Academy of Management Review, 24: 522-537.

Cunningham, G, Dixon, M., Singer, J., Oshiro, K., Ahn, N. and Weems, A. (2019) 'A site to resist and persist: Diversity, social justice and the unique nature of sport', Journal of Global Sport Management, In Press. 
Dahl, J., Kock, S. and Lundgren, E. (2016) 'Conceptualizing coopetition strategy as practice: A multilevel interpretative framework', International Studies of Management and Organization, 46(2-3): 94-109.

Dalmarco, G., Ramalho, F., Barros, A. and Soares, A. (2019) 'Providing industry 4.0 technologies: The case of a production technology cluster', The Journal of High Technology Management Research, In Press.

De Carolis, D. and Saparito, P. (2006) 'Social capital, cognition and entrepreneurial opportunities: A theoretical framework', Entrepreneurship Theory \& Practice, January: 4156.

Durst, S. and Evangelista, P. (2018) 'Logistics knowledge management: State of the art and future perspectives', Knowledge Management Research \& Practice, 16(4): 427-434.

Edvardsson, B., Tronvoll, B. and Gruber, T. (2011) 'Expanding understanding of service exchange and value co-creation: A social construction approach', Journal of The Academy of Marketing Science, 39(2): 327-339.

Escamilla-Fajardo, P., Núñez-Pomar, J. M., Prado-Gascó, V. J., and Ratten, V. (2019) 'HRM versus QCA: what affects the organizational climate in sports organizations?', Sport in Society, $1-17$.

Fakhar-Manesh M., Pellegrini M.M., Marzi G., and Dabic M. (2019) 'Knowledge management in the fourth industrial revolution: Mapping the literature and scoping future avenues', IEEE Transactions on Engineering Management, online first, DOI:10.1109/TEM.2019.2963489.

Freeman, E. (1994) 'The politics of stakeholder theory: Some future directions', Business Ethics Quarterly, 409-421.

Gold, A., Malhotra, A and Segars, A. (2001) 'Knowledge management: An organizational capabilities perspective', Journal of Management Information Systems, 18(1): 688-698.

Gronroos, C. (2012) 'Conceptualising value co-creation: A journey to the 1970s and back to the future', Journal of Marketing Management, 28(13-14): 1520-1534.

Hemme, F., Morais, D., Bowers, M. and Todd, J. (2017) 'Extending sport-based entrepreneurship theory through phenomenological inquiry', Sport Management Review, 20(1): 92-104.

Holbrook, M. (1999) 'Introduction', In Consumer Value: A Framework for Analysis and Research, Holbrook, M. (Ed), Routledge, London, p1-28.

Huertas González-Serrano, M., Jones, P. and Llanos-Contrera, O. (2020) 'An overview of sport entrepreneurship field: a bibliometric analysis of the articles published in the Web of Science', Sport in Society, 23(2), 296-314.

Jaklic, J., Grubljesic, T. and Popovic, A. (2018) 'The role of compatibility in predicting business intelligence and analytics intentions', International Journal of Information Management, 43: 305-318.

Jansen, J., Van Den Bosch, F. and Volberda, H. (2005) 'Managing potential and realized absorptive capacity: How do organisational antecedents matter?', Academy of Management Journal, 48(6): 999-1015. 
Jashapara, A. (2010) Knowledge Management: An Integrated Approach, Financial Times Press.

Johnson, G., Langley, A., Melin, L. and Whittington, R. (2007) Strategy as a practice: Research Directions and Resources, Cambridge University Press, Cambridge.

Jones, P., Jones, A., Williams-Burnett, N. and Ratten, V. (2017) 'Let's get Physical: stories of entrepreneurial activity from Sports coaches/instructors', International Journal of Entrepreneurship and Innovation, 18(4): 219-230.

Jones, P., Ratten, V., Klapper, R., and Fayolle, A. (2019). Entrepreneurial identity and context: Current trends and an agenda for future research. The International Journal of Entrepreneurship and Innovation, 20(1):3-7.

Koronios, K., Kriemadis, A., Dimitropoulos P. and Papadopoulos A. (2019) 'A values framework for measuring the influence of ethics and motivation regarding the performance of employees', Business \& Entrepreneurship Journal, 10(1): 1-19.

Koronios, K., Kriemadis, A. and Papadopoulos, A. (2019) 'Exploring service quality and its customer consequences in the sports spectating sector', Journal of Entrepreneurship and Public Policy, 8(1): 187-206.

Lane, P., Koka, B. and Pathak, S. (2006) 'The reification of absorptive capacity: A critical review and rejuvenation of the construct', Academy of Management Review, 31: 833-863.

Lazzarotti, V., Manzini, R. and Pellegrini, L. (2015) 'Is your open innovation successful? The mediating role of a firm's organizational and social context', The International Journal of Human Resource Management, 26(19): 2453-2485.

Lusch, R. and Nambisan, S. (2015) 'Service innovation: A service-dominant logic perspective', MIS Quarterly, 39(1): 155-175

Martin, R. (2010) 'Design thinking: Achieving insights via the "knowledge funnel"', Strategy \& Leadership, 38(2): 37-41.

Miragaia, D, Da Costa, C.D.M. and Ratten, V. (2018) 'Sport events at the community level: A pedagogical tool to improve skills for students and teacher', Education and Training, 60(5): 431-442.

Miragaia, D., Ferreira, J. and Ratten, V. (2017) 'Sport Event Sponsorship and Policy: A Social Entrepreneurship and Corporate Social Responsibility Perspective', International Journal of Sport Policy and Politics, 29(4): 613-623.

Nambisan, S., Wright, M. and Feldman, M. (2019) 'The digital transformation of innovation and entrepreneurship: Progress, challenges and key themes', Research Policy, In Press.

Nonaka, I. and Takeuchi, H. (1995) The knowledge creating company: How Japanese companies create the dynamics of innovation, Oxford University Press, New York.

Ordanini, A., Rubera, G. and Sala, M. (2008) 'Integrating functional knowledge and embedding learning in new product launches: How project forms helped EMI music', Long Range Planning, 41(1): 17-32.

Pellegrini, M.M., Rialti, R., Marzi, G. and Caputo, A. (2020) 'Sport Entrepreneurship: A Synthesis of Existing Literature and Future Perspectives', International Entrepreneurship and Management Journal, online first, DOI: 10.1007/s11365-020-00650-5 
Perez-Lopez, S. and Alegre, J. (2012) 'Information technology competence, knowledge processes and firm performance', Industrial Management and Data Systems, 112(4): 644662.

Radaelli, G., Dell'Era, C., Frattini, F. and Petruzzelli, A. (2017) 'Entrepreneurship and human capital in professional sport: A longitudinal analysis of the Italian soccer league', Entrepreneurship Theory \& Practice, 1-24.

Ratten, V. (2011) 'Sport-Based Entrepreneurship: Towards a New Theory of Entrepreneurship and Sport Management', International Entrepreneurship and Management Journal, 7(1): 5769.

Ratten, V. (2012) 'Sports Entrepreneurship: Towards a Conceptualisation', International Journal of Entrepreneurial Venturing, 4(1): 1-18.

Ratten, V. and Welpe, I. (2011) 'Community-Based, Social and Societal Entrepreneurship', Entrepreneurship \& Regional Development, 23(5-6): 283-286.

Rogers, E. (2003) Diffusion of Innovations, Free Press, New York.

Santoro, G., Vrontis, D., Thrassou, A. and Dezi, L. (2018) 'The Internet of Things: Building a knowledge management system for open innovation and knowledge management capacity', Technological Forecasting and Social Change, 136, 347-354.

Scaringella, L. and Burtschell, F. (2017) 'The challenges of radical innovation in Iran: Knowledge transfer and absorptive capacity highlights- Evidence from a joint venture in the construction sector', Technological Forecasting \& Social Change, 122:151-169.

Schot, J. and Geels, F. (2008) 'Strategic niche management and sustainable innovation journeys: Theory, findings, research agenda and policy', Technology Analysis \& Strategic Management, 20(5): 537-554.

Seidel, V. and Fixon, S. (2013) 'Adopting design thinking in novice multidisciplinary teams: The application and limits of design methods and reflexive practices', Journal of Product Innovation Management, 30: 19-33.

Shafia, M., Vanani, I. and Mirzaei, S. (2011) 'A model to capture the embedded knowledge of implemented projects in Iranian motor vehicle industry', Journal of Knowledge Management, 9(2): 44-56.

Skokic V. and Morrison, A. (2011) 'Conceptions of tourism lifestyle entrepreneurship: Transition economy context', Tourism Planning \& Development, 8(2): 157-169.

Song, A. (2019) 'The digital entrepreneurial ecosystem- a critique and reconfiguration', Small Business Economics, 53(3): 569-590.

Steinmueller, W. (2000) 'Will new information and communication technologies improve the “codification” of knowledge?', Industrial Corporate Change, 9(2): 361-376.

Thomason, S., Simendiger, E. and Kiernan, D. (2013) 'Several determinants of successful cooperation in small business', Journal of Small Business and Entrepreneurship, 26(1): 15-28.

Tidstrom, A., and Rajala, A. (2016) 'Coopetition strategy as interrelated praxis and practices on multiple levels', Industrial Marketing Management, 58: 35-44.

Van Praag, C. (1999) 'Some classic views on entrepreneurship', De Economist, 147: 311335. 
Vargo, S., Maglio, P. and Akaka, A. (2008) 'On value and value co-creation: A service systems and service logic perspective', European Management Journal, 26: 145-152.

Xie, C., Bagozzi, R. and Troye, S. (2008) 'Trying to prosume: Toward a theory of consumers as co-creators of value', Journal of the Academy of Marketing Science, 36(1): 109-122.

Yi, Y. and Gong, T. (2018) 'Customer value co-creation behaviour: Scale development and validation', Journal of Business Research, 66(9): 1279-1284.

Zahra, S. and George, G. (2002) 'Absorptive capacity: A review, reconceptualization and extension', Academy of Management Review, 27(2): 185-203.

Zeimers, G., Anagnostopoulos, C., Zintz, T. and Willem, A. (2019) 'Organizational learning for corporate social responsibility in sport organisations', European Sport Management Quarterly, 19(1): 80-101. 